\title{
Wind tunnel studies of gas dispersion from ground level source
}

\author{
Petr Michálek $^{1, \mathrm{a}}$ and David Zacho ${ }^{1}$ \\ ${ }^{1}$ Výzkumný a zkušebni letecký ústav,a.s. (VZLU), Department of aerodynamics, Beranových 130, 19905 Praha 9 , \\ Czech Republic
}

\begin{abstract}
Measurements of gas dispersion from ground source were performed in a boundary layer wind tunnel in VZLU Prague. The measurements include non-buoyant gas dispersion behind a ground level source on a flat plane, on a simple rectangular building model and behind a model hill and rectangular barrier. These measurements will serve for verification of a new gas dispersion software being developed in VZLU. The dispersion model is intended for use by firemen and ambulance services in the case of an accident for immediate estimation of the area with dangerous gas concentration. The dispersion model will use precalculated results for chosen areas in the Czech Republic with industrial plants and residential building in the neighborhood. The size of contaminated area will be estimated using actual meteorological situation, i.e. wind speed and direction etc. and precalculated data of flow and dispersion in the chosen location.
\end{abstract}

\section{Introduction}

A new gas dispersion model using Navier-Stokes equations with k-omega turbulence model and dispersion equations is being developed in VZLU. The model will be able to calculate flow and dispersion of dangerous gases in an urban environment in chosen areas in Czech Republic near some large chemical and power plants. In case of an accident with gas leakage the software will use pre-calculated results of flow in affected area together with actual meteorological situation to predict most endangered areas with possible fatal gas concentration. Presented paper is part of experimental studies made for the purpose of correct functionality verification of the dispersion model and for boundary conditions determination.

\section{Boundary layer wind tunnel in VZLU}

The boundary layer wind tunnel (BLWT) is a special wind tunnel designed for building and civil engineering structures testing and for dispersion experiments. BLWT in VZLU can simulate atmospheric boundary layer in neutral thermal condition for agricultural, suburban or urban terrain according to Eurocode 1 [1] and ASCE publication No. 67 [2]. The tunnel is $15.6 \mathrm{~m}$ long, $1.8 \mathrm{~m}$ wide and 1.5 high with adjustable ceiling height. It is powered by $55 \mathrm{~kW} \mathrm{DC}$ fan and maximal velocity above the boundary layer is ca. $27 \mathrm{~m} \mathrm{~s}^{-1}$. Scheme of the wind tunnel is in figure 1.
First studies concerning plume dispersion were carried out in VZLU by Jirsak and Ulman [3]. A study about gas dispersion in urban area by Ulman et al. [4] proved that the BLWT in VZLU is a suitable tool for such experimental work. Many experimental studies of gas dispersion were done worldwide, but there are few studies which investigated dispersion from ground level point source, e.g.by Roberts and Fryer-Taylor [5], Hall et al. [6] and Lawton and Robins [7].

We have studied in this project gas dispersion on a flat plane [8] and a simple rectangular model building [9]. Next step was to include a simple terrain shape, such as a terrain wave (two-dimensional hill) or an inclined plane or a rectangular barrier.

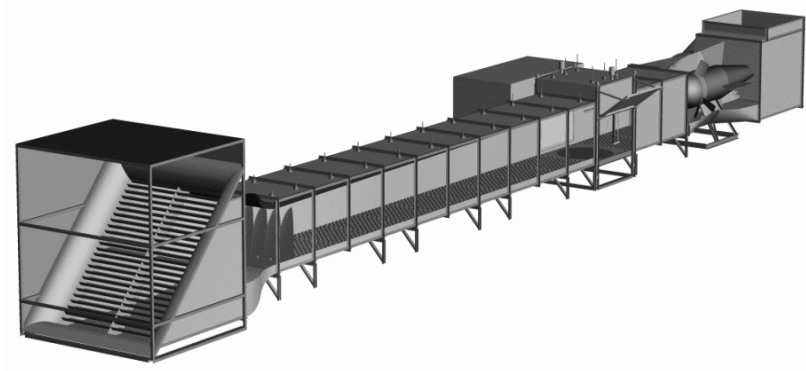

Figure 1. The BLWT in VZLU Prague.

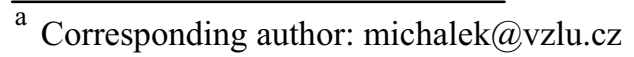




\subsection{The boundary layer simulation}

Boundary layer entering model section must be fully developed, i.e. the vertical mean velocity profile must correspond with the logarithmic or exponential law, in order to simulate the real atmospheric boundary layer. The logarithmic law is defined for indifferent atmospheric layering as

$$
U(z)=\frac{u^{*}}{k} \ln \left[\frac{z-d}{z_{o}}\right],
$$

where $u^{*}$ is frictional velocity (dynamic velocity) $\left[\mathrm{m} \mathrm{s}^{-1}\right]$, $k$ is von Karman's constant (0.4), $z_{0}$ is frictional height (aerodynamic roughness) [m], $d$ is zero plane displacement $[\mathrm{m}], U$ is mean velocity $\left[\mathrm{m} \mathrm{s}^{-1}\right]$ and $z$ is vertical coordinate $[\mathrm{m}]$.

The boundary layer has to accomplish the overcritical Reynolds roughness number $R e^{*}=\mathrm{z}_{0} \mathrm{u}^{*} / \mathrm{v} \geq 2.5$, where $v$ is cinematic viscosity of air $\left[\mathrm{m}^{2} \mathrm{~s}^{-1}\right]$. For the purpose of gas dispersion modelling this condition can be relaxed up to $R e^{*} \geq 1.0$ according to ASCE No.67 [2]. Suburban boundary layer was used for dispersion experiments described in this paper. This boundary layer was created with $13 \mathrm{~m}$ long plastic insulation sheet with $7 \mathrm{~mm}$ high cones and rectangular barrier $140 \mathrm{~mm}$ high at the test section beginning, where the boundary layer starts to evolve. The boundary layer vertical mean velocity profile is presented at figure 2 , where $U_{\epsilon}$ is velocity above the boundary layer $\left[\mathrm{m} \mathrm{s}^{-1}\right]$ and $I_{u}$ is intensity of turbulence [-]. This vertical velocity profile was measured with hot-wire anemometer with single wire probe.

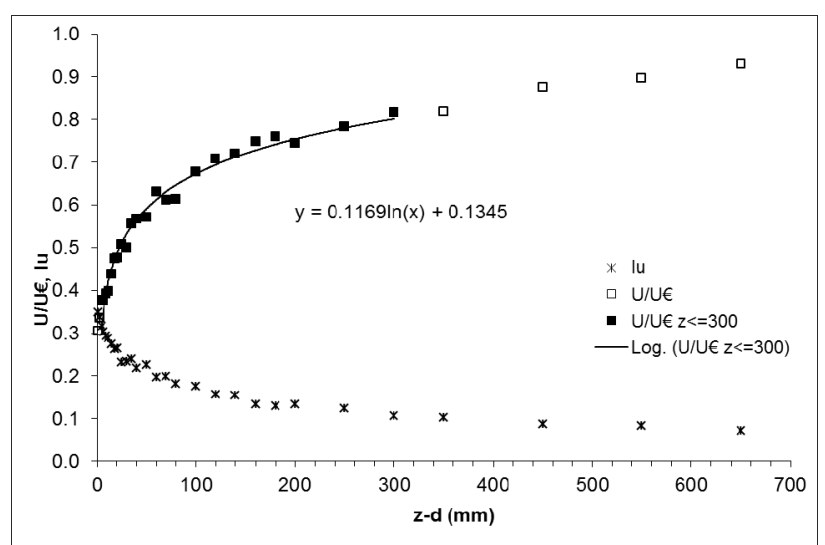

Figure 2. Vertical mean velocity profile.

Third necessary condition for modelling turbulent boundary layer is that the power spectrum of the boundary layer contains the so-called "inertial subarea", which means that part of the power spectral density agrees with the "-5/3-power slope curve". The power spectral density for height $300 \mathrm{~mm}$ is shown at figure 3 . The slope of the inertial subarea showed good agreement with von Karman spectrum as well as the Eurocode 1 spectrum.

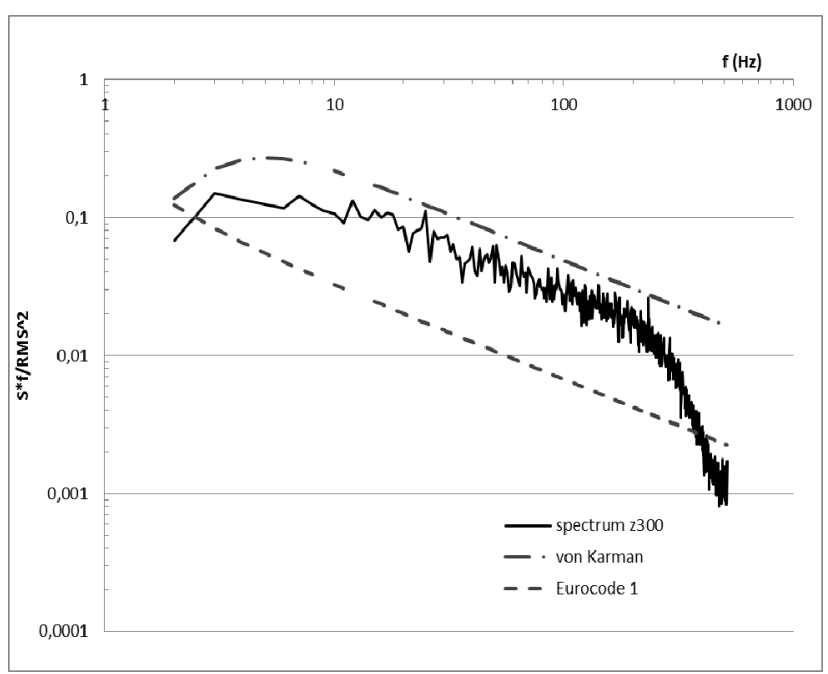

Figure 3. Power spectral density.

\section{Experiment descriptions}

\subsection{The 2D model barrier and hill}

Models of two-dimensional barrier and hill were constructed and mounted in the wind tunnel. The shape of the hill is one half of a sine wave with height to width ratio 1:4, i.e. the height is $110 \mathrm{~mm}$ and width is $440 \mathrm{~mm}$. The length of the hill was the same as the tunnel width $1.8 \mathrm{~m}$. The entire model hill was covered with the same plastic sheet with cones as in the test section. The model hill was mounted at the beginning of model section, i.e. the section with windows on both sides. The rest of the model section was covered with the sheet with cones too. The model hill with emission source mounted on windward side bottom is presented at figure 4; main wind flow is from right to left.

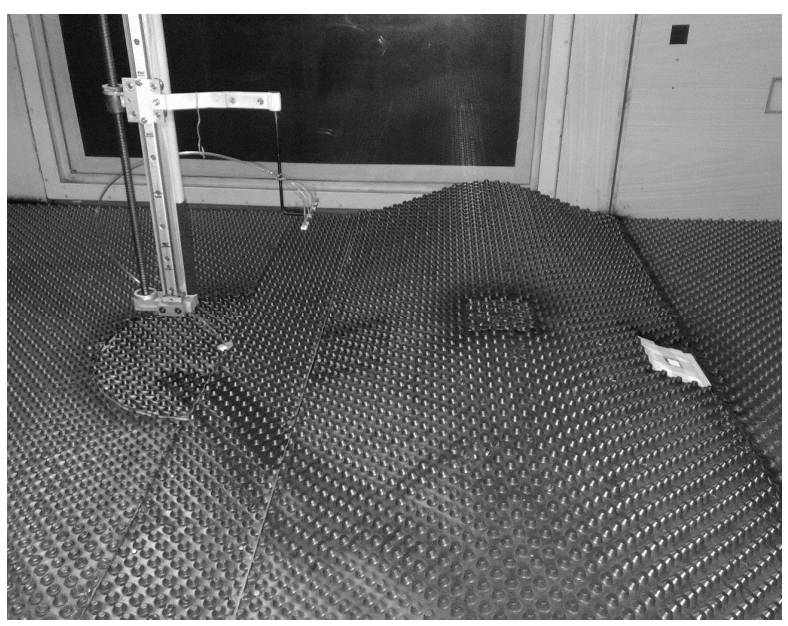

Figure 4. Model of the hill in the wind tunnel with emission source on windward side, comb probe on the left.

The barrier has a cross section of a rectangle with dimensions $100 \times 40 \mathrm{~mm}$ (height $\times$ depth). The barrier was mounted across the entire model space, which is 1.8 $\mathrm{m}$ wide. The $2 \mathrm{D}$ barrier was mounted $100 \mathrm{~mm}$ in front of or $100 \mathrm{~mm}$ behind the emission source. The entire model space was covered with the same plastic sheet with cones. 
The barrier in the wind tunnel with emission source behind it is shown at figure 5; main flow is from right to left.

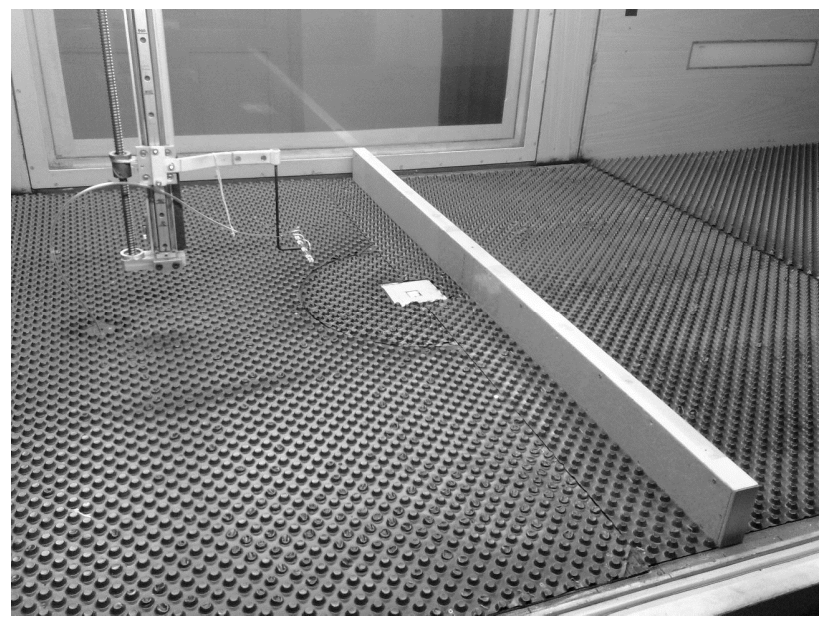

Figure 5. The 2D barrier in front of the source.

\subsection{Emission source and measuring chain}

The emission source consisted of small chamber sized 30 $\times 30 \times 10 \mathrm{~mm}$ whose one side with rectangular size $25 \times$ $25 \mathrm{~mm}$ was covered with porous fabric used in aircondition filters. The source was connected via plastic tube to flow controllers, which supplied accurate volume flux of compressed air mixed with tracer gas - ethane. The source was mounted either on top of the hill or on windward or leeward side.

To measure the concentration field above and behind the hill, a comb probe was mounted on a traversing mechanism, thus allowing movement of the probe in all three directions. The probe consisted of four suction tubes, which were connected via silicon capillary tubes with internal diameter $0.53 \mathrm{~mm}$ to a peristaltic pump and then to four flame ionisation detectors (FIDs). The FIDs converted sample flowing through the tubing into electric signal and the signal was recorded in computer. Suction tubes in the comb probe were placed $40 \mathrm{~mm}$ from each other. Vertical and horizontal concentration field in the range $\mathrm{x}=-1000(-100)$ to $400(600) \mathrm{mm}, \mathrm{y}=-480$ to 480 $\mathrm{mm}$ and $\mathrm{z}=25$ to $250(450) \mathrm{mm}$. The grid of measuring points was divided into vertical and horizontal profiles. Each point was sampled for $60 \mathrm{~s}$ with frequency $100 \mathrm{~Hz}$. Velocity above the boundary layer was set to $4 \mathrm{~m} \mathrm{~s}^{-1}$. The FIDs were calibrated using calibration gas with precise concentration $100 \mathrm{ppm}$ (parts per million) of ethane in air. Gas flow into the source was constant at $5.11 \mathrm{~min}^{-1}$ of air and $0.251 \mathrm{~min}^{-1}$ of ethane, so the total source gas flow rate was $5.351 \mathrm{~min}^{-1}$.

\section{Results}

Plot of concentration field in vertical (XZ) plane in wind tunnel vertical symmetry plane with emission source on windward side is presented in figure 6 , the source in front of the barrier in figure 7 and the source behind the barrier in figure 8 . The plot shows increased tracer gas concentration near centre of windward side and its dispersion above and behind the hill. Concentrations are plotted in ppm of ethane in air; main flow direction is from left to right. Crosses indicate measuring points. Concentration values less than 50 or $100 \mathrm{ppm}$ are not displayed. Figure 6 indicates the size of concentration field and the fact that the highest concentration is in area near the source in windward position on the hill. Emission is then dispersed over the hill and slowly diluted in the wake area.

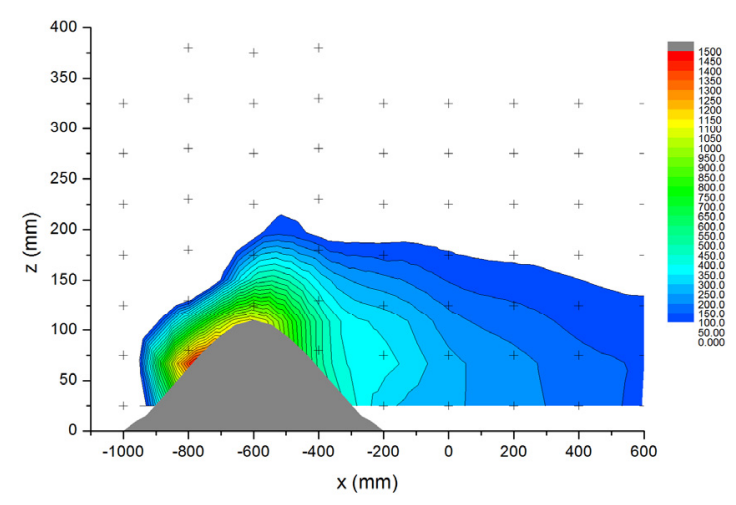

Figure 6. Concentration field above the hill in vertical plane, windward side source.

Figure 7 presents concentration field around a rectangular barrier with emission source in front of the barrier. The plot shows highest concentrations between the source and the barrier and dilution of the emission in the wake of the barrier.

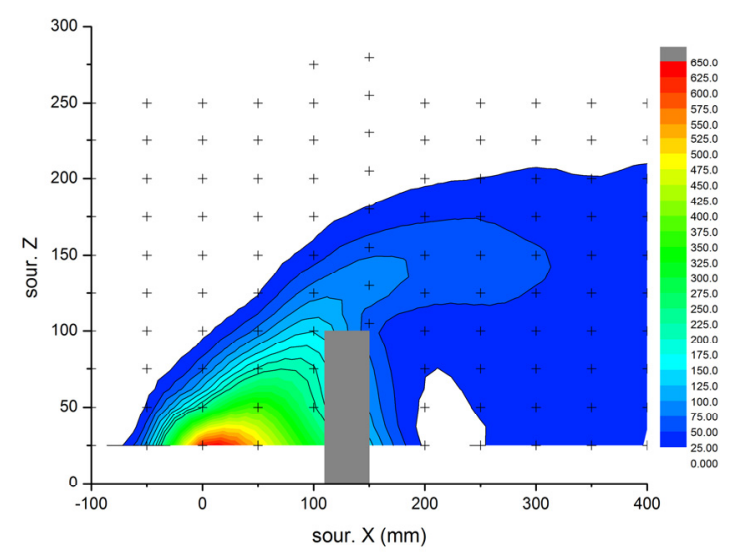

Figure 7. Concentration field with source in front of the barrier

Figure 8 presents concentration field behind the barrier, when the source is located behind the barrier. In this case the concentration remains high in the wake and is slowly dispersed here.

\section{Conclusions}

A boundary layer wind tunnel study was made to investigate flow and gas dispersion over a two dimensional model hill and a rectangular barrier. The emission source was built in the model hill on windward side and located in front of or behind the barrier in main flow direction. Significant differences in concentration 
field sizes and concentration values were found in concentration field shapes as well as in concentration values. Further experimental work will include experiments on terrain models of real urbanised area.

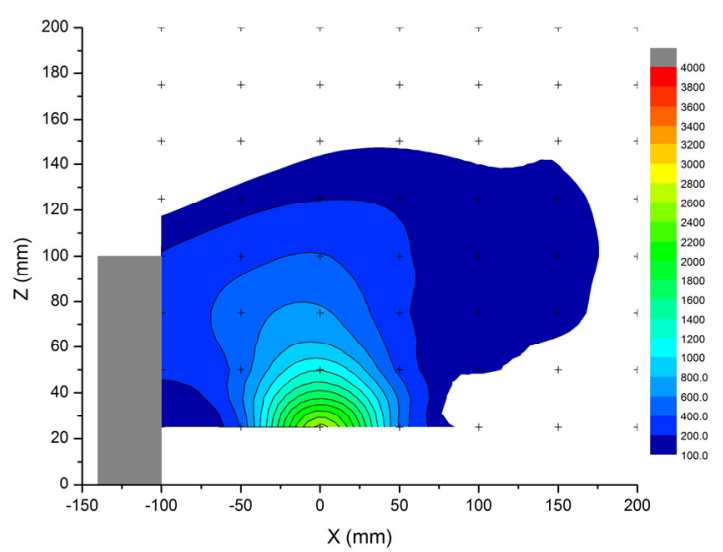

Figure 8. Concentration field with source behind the barrier

The presented results and measurements are to be used for testing and verification of the in-house developed software for the passive gas mixture flow in 2D and 3D. The software (in development) is focused on the numerical solution of the compressible gas flow in the gravitational field, uses finite volume method for the solution of the Reynolds-Averaged Navier-Stokes equations with the k-omega or EARSM turbulence models, together with the additional equation describing mass conservation of the additional gas specie. It uses special handling of the boundary conditions, based on the analysis of the Riemann problem; see Kyncl and Pelant $[10,11]$. The comparisons are subject of our future work.

\section{Acknowledgement}

This work was supported by Ministry of the Interior of Czech Republic under project no No. VG20122015098 "Scent".

\section{References}

1. Eurocode 1: Actions on structures - Part 1-4: General actions - Wind loads (EN 1991-1-4), European Committee for Standardisation, Brussels (2005)

2. Wind tunnel studies of buildings and structures, ASCE manuals and reports on engineering practice No.67, N.Isyumov (ed.), Virginia (1999)

3. M. Jirsak, R. Ulman. Advances in Air Pollution XI, WIT Transactions on Ecology and the Environment 66 (2003)

4. R. Ulman, J. Drbohlav, D. Zachoval, Proceedings of $7^{\text {th }}$ UK Conference on Wind Engineering, eds. I. Taylor and M. Vezza, Glasgow, pp. 201-204 (2006)

5. P.T. Roberts, R.E.J. Fryer-Taylor. Atmospheric Environment 28, pp.1861-1870 (1994)

6. D.J. Hall, V. Kukadia, S. Walker, P. Tilz, G.W. Marsland, Physmod 2007 (2007)

7. T. Lawton, A. Robins, Physmod 2007 (2007)

8. P. Michalek, D. Zacho, Air Pollution XX, WIT Transactions on Ecology and the Environment 157 (2012)

9. P. Michalek, D. Zacho, Fluid structure interaction VII, WIT Transactions on The Built Environment 129 (2013)
10. M. Kyncl, Numerical solution of the three-dimensional compressible flow. Ph.D. thesis, MFF UK, Prague (2011)

11. M. Kyncl, J. Pelant, Implicit method for the 3d RANS equations with the k-w (Kok) Turbulent Model, Technical report R-5453, VZLU, Prague (2012) 